\title{
I Want a Personal Information Pod
}

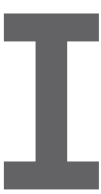

FOUND MUCH to agree with in Stephen Davies's article "Still Building the Memex" (Feb. 2011) but also feel one of his suggestions went off in the wrong direction. Davies imagined that a system for managing what he termed a "personal knowledge base" would be a "distributed system that securely stores your personal knowledge and is available to you anywhere..." and toward this end dismissed handheld devices due to their hardware limitations while including handheld devices as a way to access the networked distributed system.

Just as Davies might have imagined future built-in network capabilities able to guarantee access anywhere anytime at desirable speeds to the desired information (presumably at reaonable cost), the rest of us, too, can imagine personal devices with all the necessary capabilities and interface control. Such devices would be much closer to Vannevar Bush's Memex vision.

Bush was clearly writing about a personal machine to store one's collection of personal information, and a personal device functioning as one's extended memory would be far preferable to a networked distributed system. But why would any of us trust our personal extended memory to some networked distributed resource, given how often we are unable to find something on the Web we might have seen before?

In my own exploration of Bush's Memex vision ("Memex at 60: Internet or iPod?" Journal of the American Society for Information Science and Technology (July 2006), 1233-1242), I took a stab at how such a personal information device might be assembled and function, comparing it to a combination iPod and tablet PC, resulting in a personal information pod.

Ultimately though, I do fully agree with Davies as to the desirability of a tool that benefits any of us whose "own mind" is simply "insufficient for retaining and leveraging the knowledge [we] acquire."

Richard H. Veith, Port Murray, NJ

\section{Author's Response:}

Veith makes a fair point. For users, what ultimately matters is whether their knowledge base is ubiquitously available and immune to data loss-as provided by the distributed solution I described but that would be handled just as well by a handheld device with synchronized backups.

Stephen Davies, Fredericksburg, VA

\section{More Industrial Researchers at Conferences and Workshops}

Moshe Y. Vardi's Editor's Letter (Jan. 2011) posed the possibly rhetorical question "Where Have All the Workshops Gone?" Just as business strategy is influenced by tax law, the nature of workshops is determined, in part, by academic- and corporate-funding policies. Corporate attendance at an external (to the organization) conference or workshop is often driven by whether a mainstream research paper has been accepted for publication in its proceedings. Likewise, academic promotions and salary increases at research universities are influenced by whether a paper was published in "first tier" conference or workshop publications. These policies are mainly responsible for the demise of the type of workshop Vardi described.

I have found, at least in my company, that enlightened management encourages the free exchange of ideas and best practices at such workshops, even though they are typically closed events due to IP concerns. However, organizing them so they're indeed open to the public and attract attendees and speakers likely requires a change in promotion and tenure policies at universities and a value proposition that encourages participation by industrial researchers.

Brian Berenbach, Princeton, $\mathrm{NJ}$

\section{Correction}

Due to an editing error, the letter to the editor by Paul McJones "Credit Due for Tandem's Hardware and OS"
(Feb. 2011) transposed technical credit cited for James A. Katzman and Joel F. Bartlett at Tandem in the late 1970s. Katzman and Bartlett were key contributors on hardware and operating system, respectively.

Communications welcomes your opinion. To submit a Letter to the Editor, please limit your comments to 500 words or less and send to letters@cacm.acm.org.

(C) 2011 ACM 0001-0782/11/04 \$10.00

Coming Next Month in

COMMUNICATIONS

Brain-Computer

Interfaces for

Communication

and Control

The Future of

Microprocessors: Changing

Technology Landscape

Shapes the Next 20 Years of

Microprocessor Architecture

Proving Program Termination

Privacy-Preserving

Network Forensics

An Interview with

Steve Furber

Viewpoint: The Importance

of Reviewing the Code

And the latest news on domestic-assistance robots, computational metaphysics, large-scale organization of photos, and artificial intelligence for developing nations. 